\begin{tabular}{|l|l|l|l|l|}
\hline \multirow{2}{*}{ aptara } & CUAN & cuan_1161 & Dispatch: September 10, 2012 & CE: N/A \\
\cline { 2 - 5 } & Journal & MSP No. & No. of pages: 25 & PE: Sarah \\
\hline
\end{tabular}

\title{
THE TIME OF ANTHROPOLOGY: Notes from a Field of Contemporary Experience
}

\author{
ANAND PANDIAN \\ Johns Hopkins University
}

Sometime ago - I'm not sure when - I was struck by the strangeness of our experience of time. It may have been in the space hollowed out by three bay windows, looking out onto a row of aging Victorian houses and a Jack in the Box on the corner of a street in North Oakland, California. There were burger wrappers and bits of plastic gusting across the lawn every now and then, but these were mostly abstract forms and forces. Visible through them was a world of paddy cultivators and itinerant herdsmen, banana groves and dry stubbled fields, scarred green slopes and flowing brown waters, in the distant valley in South India where I had spent most of the previous two years. Like the bored and the lovelorn, nostalgic and dreaming, I was in one place, thinking of another. But in this sitting before a blue-green iMac, in the idling, rustling and sometimes typing what would become a dissertation, life in the present had become an enlivening of the past - to be opened, imagined, thought, and inhabited, even as it remained stubbornly unclear what it was and could yet be.

This article concerns the question of newness in anthropology, and how we might understand its emergence in the diverse worlds of experience we encounter and engage. ${ }^{1}$ This is a concern that many of us share, especially with the development of a "contemporaneous anthropology," which begins, as Marc Augé writes, with the acknowledgment that "the other changes" along with us. ${ }^{2}$ This simple yet belated acknowledgment has posed grave challenges for a discipline accustomed to tacking between conceptual and empirical elaboration: What forms of thought could possibly keep pace with the boundless forms of change visible everywhere we 
turn? With what resources can we think about emergence when our own concepts betray so often the temptations of the familiar, the customary, and the inertial?

Arguably, these are foundational problems for the discipline now. Consider, for example, the attention that Anne Allison and Charles Piot call to "times as volatile, speeded up, and precarious as the present" in their 2011 inaugural statement as editors of Cultural Anthropology; the development of an "anthropology of the contemporary" attuned specifically to such conditions of emergence; or the prevalence of "becoming" as a central theme of recent work in anthropology. ${ }^{3}$ Potential relevance to the novel conjunctures of the present, incipient forms of attention to modes of emergence and becoming, ethicopolitical commitments to the difference and originality of other modes of modern life elsewhere: here are some of the grounds on which newness has been staked as a problem in contemporary anthropology.

We may seek, under these circumstances, to give ourselves over to the apparent momentum of the present, to seek new horizons of thought among those persons, objects, and situations that seem to propel most forcefully the dynamism of the contemporary. ${ }^{4}$ But this is a leap we need not make. I argue that we may come to see newness most vividly not by searching for what is new but, instead, by attending more carefully to the ways in which it arises in what we already do. I seek, in other words, to refocus our care for the new, away from the apparent novelties of the present, and toward the temporal textures of experience through which newness is encountered in the first place. This article is less concerned with the difference of a time yet to come, than with its place in the time that is already ours to experience.

Now. A note from the field of this article's reading: your reading of this article. A digression in the body of the text, an interruption in the experience of its passage, and a fissure, perhaps, in your trust of its author. Still, a warning seemed necessary. This article pursues certain narrative devices that are meant to express and embody its argumentative stakes and conceptual architecture. Methodological innovation in contemporary anthropology is inextricable from questions of expressive form. I imagine you involved, as you read, in the time about which I'm writing. There are sensations, impressions, of flow, cut, loss, and return that have everything to do with how we encounter experience and its potential for difference.

There is an anthropology of time, concerning the presence, force, and weight of the past in contemporary cultural life, the divergent future horizons inflecting action and anticipation, and the myriad ways in which people reckon, regulate, and 
inhabit the passage of the present. ${ }^{5}$ This article, however, is an exploration of the unfolding of anthropology in time, or, better yet, the time of anthropology: the temporal horizons of our own work and thought, as they unfurl in our relations with others and in the distance we assume to ourselves. Rather than taking temporalityritual, calendrical, linear, or cyclical — as yet another quality or property of the objects we seek to understand, I hope to confront time as the generative weave of what we feel and do, trespassing any clear line that might be drawn between subjects and objects of anthropological research.

Johannes Fabian famously diagnosed a "schizogenic use of Time" in anthropology: field ethnography depended on a sharing of communicative time, he argued, while ethnographic narrative tended to place its subjects "in a Time other than the present of the producer of anthropological discourse." ${ }^{\prime 6}$ I do not seek here a means of restoring "coevalness" to the temporal relationship between anthropologist and field interlocutor, as Fabian had proposed so compellingly. Instead, I pursue a few ways of acknowledging the productivity of this gap in time. What do we find as our partial immersion in the time of others splits ourselves apart?

It is well known that anthropology takes time - perhaps far too much - and therefore demands patience - perhaps again, far too much - from its exponents and their interlocutors. The encounters so consequential in what we do, encounters with life, thought, sensation, and experience, unfold in a time whose vicissitudes become our own. Both the vexation and the promise of so disposing oneself to time is succinctly conveyed by an aphorism of Henri Bergson concerning another immersive medium: "If I want to mix a glass of sugar and water, I must, willy-nilly, wait until the sugar melts."

Bergson sought to make visible the creative and inventive quality of time: the emergent yield of its duration, through which thought— like life and art — develops into unforeseen forms. In what follows, I engage time as a horizon of experience in which things and beings come to differ from themselves, a movement of invention through which things affect, modulate, and transform themselves and each other. ${ }^{8}$ I focus most closely on four ways that we may experience such change, or the emergence of such newness. The time of anthropology is inventive, I suggest, insofar as it is untimely, contemporary, present, and virtual.

This can also be put more simply. We need time that ripens, flows, beats, and wafts.

This article unfolds as a series of experiments in time: more specifically, in the temporal fields of anthropological fieldwork, writing, teaching, and readingintertwined and interrelated modes of thought, action, and attention. Each of these 
instances yields a certain way of both imagining and inhabiting time: some means of confronting a dimension of its generative force from within the temporal texture of an experience. These moments of potential clarity are pursued in a mood of conviction drifting constantly into deep unease. They are happenings in the life of a recent initiate. Dwelling on the words of varied teachers, they concern some of my encounters with the temporality of an anthropological education. And they often assume the form of notes to myself: glimpses of a confused and faltering rehearsal of arguments yet to come.

October 12, 2011. People have already found this article frustrating. But this is what Michael Jackson said, with startling clarity. He said that it seems to move like the Warlpiri hunt: not in a progressive line from beginning to end, but as a series of circular movements, differential yet repetitive, whorls and eddies, approaching now and again the texture of an experience. Remember to say this at the beginning, as an invitation to the reader: this may take some time, you might have to get a bit lost here.

I turn to such field notes for help with the problem of newness, oddly more elusive than ever now that the chase has truly begun. In a return to his Colombian field diaries, Michael Taussig writes of recollected images that "mesh with recent experience so as to elicit aleatory significance, as with a basin full of water becoming the sea." ${ }^{\prime}$ Here, I turn to a few fragments of my notes - taken from moments of fieldwork, and amid reading and writing - as a way of bringing into focus certain transformative experiences of time that are easily obscured by the narrative consolidation of ethnographic texts. ${ }^{10}$ It is their, my, susceptibility to the vicissitudes of happening - to the wash, tide, wave, or drift of experience - that draws me to them.

Later. Dare I speculate? You've already read this article, maybe grazed it and put it aside for still later, maybe you threw it aside, in your head or along the table, who can say. What remains of what write? When does the anthropology happen? Our works depend on what has already happened, and yet, as we confront these texts as finished and unfinished forms, as we read, write, think, and speak, with and against them, sometimes something more will happen, something else, unexpected and unforeseen, the event of a thought, the progress of a field science. The field ... where does it begin, when does it end? Is it less a matter of being there than being then? ${ }^{11}$

All of this may seem too cryptic or solipsistic. It may also seem like an anachronistic return to a "mythos" of adventure and encounter out of joint with the

times. ${ }^{12}$ In its form, feel, and language, however, this article is composed with the 
hope of showing something of how time opens us beyond ourselves. I can think of no better way of excavating the significance of time in anthropology than by dwelling on such moments and instances - ragged, awkward, vulnerable, unfinished — of entanglement in its flux. For Claude Lévi-Strauss, here was the anthropological formula: "I is another." ${ }^{13}$ Borrowed from a poet, a devotion to experience for its promise of the unknown - this is how we come to see the reinvention of the world. ${ }^{14}$

\section{UNTIMELY, OR RIPENING}

October 2001. My dissertation fieldwork notes from the Cumbum Valley in south India record a stream of proverbs, an encounter with a monkey, a local haircut, Gandhi's birthday, the heated unfolding of a village election campaign, the dropping of U.S. bombs far to the north, and the daily plowing and sowing, tract by tract, of a vast expense of flat paddy land across the river to the west. There is the feeling at times of something developing: shared laughs, reverberating ideas, feet sinking slowly into the grey muck of the fields under cool grey skies. But there is also fraying patience and depressive lethargy, echoing the tumult and despair in leaking and neglected local schools, and the many who had described dropping out of this charade, picking up a spade or sickle but sending their own children back to the same school grounds with the vain hope that they would become something else.

It was difficult to avoid thinking about my own trajectory, and a time of progress that seemed to be slipping away. What ensued one afternoon was a passage of writing that grips me still with fascination and shame-

Mookiah, sitting on a cement irrigation canal while his bulls grazed their way down to the riverbank, asked me "Why are you wandering around like this, like a waste?" Not a day goes by without my asking myself the very same question. And now, as I wheeze, pick out a fallen hair of my ugly fat mustache from my mouth, sneeze, sniffle, and blow from a budding cold, and flex a big toe with dirty aching cracks running across its bottom, struggling to recall even the most banal of English words such as "cracks" to describe myself to myself, I wonder again what it is that I hope to illumine concerning the human condition, or some small portion of it, with the aid of these poor, frustrated, struggling, suffering people... My informants tell me again and again that their time isn't right ... Countless lives here, caught at the wrong time. I can't help but think, as I look out at ploughs churning through the mud, at women bent over sowing fields bit by bit, at farmers and their farming, that these are living relics, detritus caught up in the slowly spinning water on the edge of the river. The machines are coming, and they will 
change the lives of these people forever. They will feel the impact-some will ride the wave, many will go under ... History is made elsewhere, and we here, myself included, are bystanders; we read the papers, watch some TV, discuss a little, and by and large go on living lives that I secretly suspect are obsolete. Does a quarrelsome rustic of this corner of the Cumbum Valley have anything to teach Americans about what kind of person to be? Perhaps I should ask. Amid the rain of 500-pound bombs, I hardly have.

One line in the middle of these mawkishly pained reflections gives a clue to their sudden eruption. I had just taken a look at a friend's dissertation outline, a project about other machines in a very different place, one that seemed more than anything else to be "timely."

Passing over my fieldwork then was the shadow of a certain kind of history, one in which, as Friedrich Nietzsche wrote, "the great moments in the struggle of the human individual constitute a chain . . . like a range of human monumental peaks." 15 For Nietzsche, an excess of such history was harmful to living beings, for it reduced the scope of active life to nothing more than an imitation of the already dead. He was a classical philologist, a "pupil of earlier times" dismayed by the "consuming fever" for nationalist history among his 19th-century German contemporaries. ${ }^{16}$ A "stepchild" of his times, Nietzsche fought "against the soldering of time-bound things on to his own untimeliness." 17 The untimely acts on and against one's own time with the hope, he wrote, of a time yet to come. ${ }^{18}$ Was there any such hope to be found in this moment of anthropological angst?

"The unhistorical is like an atmosphere within which alone life can germinate and with the destruction of which it must vanish," Nietzsche observed: the opening of a protective horizon of time against the forces of the present. ${ }^{19}$ I was lucky enough to fall within such a horizon myself as a student of anthropology. I came to the University of California, Berkeley, from a year of volunteer work in rural Tamil Nadu, where I had first encountered the contemporary developments that long remained the intended focus of my doctoral research: an India-wide "plantation bubble" in the mid-1990s in which tens of thousands of acres of rural land were seized and squandered in the name of scientific forestry. But arriving again in India in late 2000 for an extended period of dissertation research, I found that my carefully tended questions were already after the fact - most of the concerned investors, farmers, and activists had moved on, cutting their losses where they fell. Perhaps inevitably, my dissertation project became something else altogether: an examination of agrarian livelihood and moral cultivation among a community of putative thieves in the same region. ${ }^{20}$ 
In the summer of 2001, I was finally able to confront my graduate advisors with what I hoped now to do. Each was generous and supportive in a distinctive way. On a long walk in the East Bay hills, Donald Moore worked this new fieldwork situation into the grain of our ongoing conversations on processes of cultivation, training, and settling. Back in Kroeber Hall, Paul Rabinow listened as I spoke avidly of tomato plants as children and the mind as a wandering monkey. "This stuff is all over the place," he cautioned, but there was encouragement in his emphasis on my own excitement. Lawrence Cohen was enthusiastic late one night on the phone from London, but I was at a pay phone outside a club in San Francisco, hardly able to make sense of what I was doing. Later, sober, I remembered that he'd advised me to think about time.

It was impossible to avoid doing so when I returned to rural Tamil Nadu a few weeks later. Although my interlocutors still relied on floating bits of English to describe the present as a "time of computers," my own thoughts lingered on the agrarian traditions and Tamil cultural inheritances that seemed to compose the persistent sense and substance of their lives. I struggled with the question of how to convey the moral and affective charge of these quotidian tensions without echoing the prejudices of the civilized. Could I do more than to describe this complex relationship to the time of the present from the safety of a bemused distance? It was as I wrestled with such questions one October day later that year, sitting at a heavy black ThinkPad on the edge of a teak bed in an aging farmhouse, that Mookiah's question - "Why are you wandering around like this, like a waste?" — struck me so forcefully.

The young herdsman had forced me to think more carefully about what was happening just then. His question shifted the tense of my saying, from a reporting of past things that had already happened elsewhere, to a recording of what was happening immediately — not only my own wheezing, flexing, and describing but also the farming, living, and suffering of those I was writing about. Time seemed to be unfolding as an orchestration of distant forces and flows, but people here were still actively engaging these powerful vectors of influence and consequence. Looking back at this moment, it seems as if I had to be reminded of the active degradation of my own body to begin to see how one could awaken to the awkward potential borne by this time. In the months that followed, an oft-cited and melancholy line from an erstwhile Tamil film song would underscore this difficult lesson, time and again: "This is a time that ripens and passes even in its tender youth." I eventually wrote about such a ripening of people out of time, seeking to testify to ways of living on in a time that belonged to others. In the horizon of becoming that language 
had relinquished, there was space to wager the slender yet enduring possibility of another kind of life.

November 2010. AAA Book Fair. Day by day, one stack of books dwindles precipitously beside a steady tower of my own. A tale of two books, one with a pop star on the cover, the other with a woman harvesting rice by hand. My editor is frank. He is disappointed. He thinks it's the GFC — Global Financial Crisis.

Paul Rabinow has recently made a case for "resolute and ardent untimeliness" as "an important practice to foster" in contemporary anthropology. ${ }^{21}$ Through our vocation as intellectuals, he argues, we may assume "a critical distance from the present that seeks to establish a relationship to the present different from reigning opinion." ${ }^{22}$ Surely this is necessary. Still, what happens when we assume such distance? For Rabinow, loneliness is the price we pay for resolve. ${ }^{23}$ But take this task as a matter of irresolution instead, of finding oneself amid others out of joint with the times, distressed shoots seeking a climate for life. What if the distance of the untimely were less critical, in other words, than affective or pathetic in its character, bound up with the faltering development of those ripening out of time? We in anthropology so often find ourselves troubled by the fate of things that do not seem to find a footing on contemporary ground. What do we seek in the company of such others but a means of living beyond the present, some way of passing with them into a time beyond this night?

\section{CONTEMPORARY, OR FLOWING}

The contemporary means many things for anthropology now. Paul Rabinow usefully suggests that we distinguish two such meanings: "existing or occurring at, or dating from, the same period of time as something or somebody else," and "distinctively modern in style." 24 The second supports an idea of the contemporary as "a moving ratio of modernity, moving through the recent past and near future in a (nonlinear) space that gauges modernity as an ethos already becoming historical." 25 This anthropology of the contemporary attends to "an actual object domain in the present whose recent past, near future, and emergent forms can be observed." ${ }^{26}$ Rabinow's reflections implicitly rely on a certain kind of relationship in time between the anthropologist and the domain of investigation: to investigate some domain of the contemporary as a moving ratio of newness, one must be contemporaneous with it in the first of these senses. We may therefore ask whether sharing the same time with one's object of investigations - being its 
For the last several years, I have been engaged in ethnographic fieldwork with South Indian popular filmmakers. Their domain - media - is often identified as an emergent field of concern in contemporary anthropology, and it is worth noting that the younger filmmakers with whom I have worked most closely have themselves been marked as composing a "New Wave" in contemporary Indian film. The milieu is one of tremendous contingency and uncertainty. As one assistant director once said to me on the floor of a set reconstructing a colonial-era train station in modern Chennai, "anything can happen at any time."

The English heroine of his film had just developed a mysterious and obvious rash on her face, stalling the entire production of this historical romance. Krishna had shrugged these words with casual and lighthearted acceptance, but they felt to me like a motto for the domain whose projects I had made my own. "What will tomorrow bring?" I had asked myself with vague and uneasy hope a few days after this minor crisis, having completed my stint of short-term fieldwork with this production. Two days later, I managed to catch an assistant director for another film project on the phone. "Come tomorrow," she said. "We just started shooting today."

When I arrived the next morning, this film crew was shooting in the basement of a large house in T. Nagar, Chennai, many of them crowded into a small room set up as an architect's study. On her breaks, the heroine sat quietly to the side, reading from Truffaut's My Life in Film. The director, meanwhile, was impassioned about his experimental approach: "We're throwing out everything that we've learned, trying to do something new. It's a romantic film: how to do something different with it?"

The film itself was a sudden development, just a few days in the making, the director improvising much of the dialogue on the set and the plot itself largely unknown to most of those involved. "Everywhere else, the sun rises in the morning and sets at night," the art director quipped by way of explanation - "but not here. Things here, they suddenly happen, all at once." Five days later, the crew shifted to the grounds of a beach resort south of Chennai, where tensions between the newlywed couple at the heart of the film were meant to intensify.

I was far more awkward and nervous with this crew than any other I had worked with till then. The relationship between this director and his cameraman was private and intense, brokered by countless cigarettes and murmured OKs as they huddled close to the screen of the live video feed. The director had selected his own brother as the hero of the film, and avid rumors attributed his impending divorce to the heroine he had cast. These were also difficult scenes of spousal 
argument and indignation that they were filming, stumbled over through wearying rounds of takes, and recurrent explosions of anger, frustration, and despair. I was working to try to capture this circulation of affective energy between the director and his leading pair. My notes, for example, recorded this exchange:

"Hit him nicely, don't fake it," T tells her. "I need an emotional outbreak. You've been quietly waiting..." It should come "like a storm."

I can recall now the sensation that I felt for a moment later that same evening at the beach resort, shortly after this particular take. There was a feeling of fullness, of a rhythm or a current that I had finally slipped into with these people and the situation they were working with, the sense that I wanted and needed to do no more than to move among them as I had been moving just then: eavesdropping on these interactions, slipping close behind the video feed at the onset of each take, stealing quick exchanges of a minute or two with the lead actor and the director when they sat back to relax, tapping additions to my notes on a handheld iPod all the while. It was as though I could feel another face of the project thickening into being. But this feeling of plenitude endured only for that moment - however long it had lasted - and then slipped into something else more unsettling.

It suddenly struck me that I had been approaching this emerging facet of the project in the wrong way, focusing far too closely on the director, rather than actors themselves. I thought back to what I found so enigmatic about the lead actor in this film, a popular figure in the Tamil film industry: his insistence on quick rounds of pushups before each bare-chested shot, the way he frowned, grimaced, and smiled his lines to himself as he rehearsed them, the novel to which he quietly retreated at every lengthy break. He like others here was known colloquially as an artiste; could I focus on his entire life as a work of art, as a way of styling himself? I prepared in my mind a series of ways that I could "pitch" this idea to him and "cast" him for this role in the book that I hoped to write. Now I wanted to do something other than what I had been doing.

I did not have the chance to approach him with this idea until the following evening. "I'll have to think about it, whether I can be so ..." he said to me, before trailing off. But as it turned out, these were the last words that we would exchange. The next night's shoot was abruptly canceled because of the threat of rain. The same thing happened without warning over the next three nights, each day calling on me to leap into a temporal abyss of indefinite depth. I tried to contact the actor through his famously spiteful agent, but I was able to wring no more than four 
words from him: "He's not reachable, ok?" By that Tuesday, I was wracked with anxiety, waiting again for news on the day, and left with little to do but to seek out company, with myself and with others, through fitful bouts of writing -

Tuesday morning, still living with uncertainty. This imperative continues to plague me, and I find that I am so poor at this, at "living" with the deep uncertainty of what may come, or may fail to come, at any moment. Monday again was a wash ... I spent the day somehow, trying fitfully to sleep on a couple of occasions, to no avail, trying to make some phone calls, to little avail ... Tuesday, 12:23, still waiting for something to happen. This waiting, maddening... I can feel the tension still coursing through my body. The shoot is off again tonight, $S$ [the cameraman] has just told me, but he also gave me one sliver of hope, in that he has spoken with $T$ on the phone and he has told him that I want to meet with R ... S said he'd call me in 10 minutes. "Should I call you in 15 minutes?" I asked $S$. He said that he would call me, and so I wait again, nervously... I enquire after 40 minutes have passed, S texts me back. "No. Not yet. I'm waiting for his call." I write him back in detail: "Must take spiritual discipline. Ok, this impatient American will learn to wait too!" His reply_-O'Oh. Sorry" - confuses me, so I write back: "What I mean is that you have all learned to adjust to uncertain circumstances rain mood accident etc in a way that I find amazing but personally a challenge"... His reply then, "Ya. It's true."

"Just go with the current... Live like the Buddha," another director later advised on the phone. This was not easy — and isn't, still — but by the end of that day, with some of his stories in mind, and further empathetic text messages from the cameraman, I felt closer to a fragile sense of equanimity. We had become more contemporary; I had learned something about sharing their time.

I have lingered on this episode to call attention to the challenge of simply being in the same time with others, and the significance of such challenges for any endeavor to capture the contemporary emergence of the new. ${ }^{28}$ We might imagine the moving ratio of the modern - to return to Rabinow's image - to move in discontinuous fits and starts, with obstacles of various kinds scattered among its streams, and whorls and eddies disrupting the smoothness of a laminar flow. In such a world of varying resistance to anthropological copresence, is there any other way of approaching the emergent than by opening oneself to its turbulence? It is a matter here of neither slowing down nor speeding up in absolute terms, but instead of finding rhythms of fieldwork - whether intermittent or continuous, fleeting or enduring, irregular or repetitive - consonant with the temporal flux of the domains we seek to understand. ${ }^{29}$ 
cuan_1161 can2008.cls September 10, $2012 \quad 17: 31$

CULTURAL ANTHROPOLOGY 27:4

February 8, 2012. When the fuck will I be done with this article?

Our contemporary is less a property of what we study and more a momentum of engagement, a dynamic, unstable, and fleeting sense of time felt in common with a world beyond ourselves. And when we seek to share in such time, we may find our attentions turning inward as well as outward. Immersion in a contemporary bends time's coordinates against itself. Among these loops and whorls, the exterior line of an approaching horizon becomes an interior fold within which to linger, fume, and sometimes reflect. Seeking contemporaneity with others, we ultimately confront the challenge of becoming contemporaneous with ourselves, of somehow coinciding in thought with the texture, depth, and pull of our own experience - a coincidence without which novelty is impossible to see, let alone think. ${ }^{30}$

\section{PRESENT, OR RHYTHMIC}

The present remains a problem in anthropology now: not as an interval between the past and the future, but as a chasm between the timeless and the timely. On the one side are those persistent fictions that would invest particular peoples, cultures, or places with an unchanging quality or structure. On the other side are those anxious imaginations that would invest our time - in an epochal sense - with a force and momentum of its own. Both of these positions tend to approach the present as a grammatical form, a matter of descriptive tense: either as an "ethnographic" present that would convey what happens somewhere as the enactment of an already perfect or complete mode of existence, or as an imperfect expression of what is suddenly or newly happening, erupting, or emergingan event that we may run along beside or tag belatedly behind, seeking to say something relevant before it becomes something else again. In both of these ways, the problem of the present is reduced to one of representation: to a matter of likeness, fidelity, or closeness to a time whose emergence has actually happened already and somewhere else, beyond our reach.

But what if the present for anthropology was something else altogether: neither the point at which the past ceaselessly reiterates itself as its own future, nor the space in which we may reach toward a future we can already see, but instead a flux of experience through which our thoughts assume unanticipated and perhaps even unknown forms?

It is in such a time that Kathleen Stewart's Ordinary Affects is set, a "reeling present" of shifting and ephemeral forces. ${ }^{31}$ We are cast almost immediately into the pulsing horizons of this time- "It's been years now since we've been 
book defies the idea that its ethnographic elaboration must have already happened in an identifiable span or space of time, giving the sense instead of time as an ongoing movement of becoming, a flux that persists even in its reading. As Stewart writes, "it's sort of like being a water bug, living on the surface tension of some kind of liquid."

In its effort to "stay in the middle of things," Stewart's work resonates closely with Henri Bergson's method of intuition. ${ }^{34}$ Bergson described intuition as the "sympathy by which one places oneself within an object in order to coincide with what is unique in it and consequently inexpressible." 35 We may come to see our inner lives as "a succession of states" of continuous flux - qualitatively different yet impossible to bound off from each other - and to encounter other things too as fluxions of thought and matter. ${ }^{36}$ Intuition for Bergson promises a particular way of approaching the present, as an "interval of duration," a movement of ceaseless and indivisible transformation. ${ }^{37}$ As Gilles Deleuze elaborates, "my own duration ... serves to reveal other durations that beat to other rhythms, that differ in kind from mine." 38

How do we in anthropology seek to intuit the flux of the present? Stewart's scenes of the ordinary are narrated not in the voice of an "I" but, instead, as the experience of a "she," one who "gazes, imagines, senses, takes on, performs, and asserts" her own attunement to these scenes. ${ }^{39}$ She shares a kinship with the affects she describes: her present ebbs and flows, reaches out and pulls away, surges and comes to a sudden halt. Such is the quality of Stewart's prose that we are startled when we are sometimes, subtly, reminded that "she" has been investigating -

She watched. They watched her watching. Then she started to sidle up to ask them what this was all about. Their faces twisted like they were used to trouble. She slid back away from them without finishing her question and moved on, troubled in many directions at once. $^{40}$

Her present is their present, her presence their presence, for what she shares with them is an attunement to the ordinary; in this, "she's no different from anyone else," Stewart writes. ${ }^{41}$ And yet we are not, after all, always and only attuned to the ordinary. What if we were listening for other, different, rhythms? What would it take to intuit their presence in relation to our own?

South Indian music composer Yuvan Shankar Raja is another figure I have worked with intermittently over the last couple of years, seeking some understanding of the processes through which his film music is composed, arranged, recorded, and released. Yuvan is a veritable rock star, a singer and artist in his own 
right, able to draw tens of thousands of young fans to stadium shows and one of the most visible promotional vehicles for his films. In person, he was always relaxed, cool, chilled — favored adjectives of his that he cultivated as both personal qualities and tokens of a measured interactive style. But legendary were the contortions into which the young and elusive music director could throw not only visiting anthropologists but also leading directors and producers in the field. As Yuvan's genial manager often put it, with bemused and exaggerated emphasis, "It all depends on Mr. Yuvan's mood."

I dropped by Yuvan's recording studio one afternoon soon after I had arrived in Chennai in the summer of 2010, planning that day only to lay out my hope for a few more glimpses of the composer at work. We chatted for a few minutes. And then, quite unexpectedly, he invited me right then into the recording booth: "Let's see how it goes." I knew nothing about what was coming (that he would begin to sing himself) or what this was meant for (a song that would become one of the great Tamil hits of 2010). But I was there, and something was happening-

$Y$ is in jeans, a dark T-shirt and fancy sneakers... Y seems to be warming up as he goes along, humming more to himself at first, then singing more softly as the engineer records and plays, then more emphatically, bouncing a bit and tapping his feet and sometimes his thighs as he stands before the console... With the spacy atmospheric music, Y layers a heavy beat, and then brings his own echoing voice back in, and then begins to play the piano. I'm shaking my head, not only the music but the amazement that I am suddenly again in a space of creation. All else is off now, save the piano, then back on again after a few notes... Suddenly he addressed me: "you like it?" to which I could only blurt out "dude, it's awesome.". . "It's coming out nicely," he says after he plays a bit now with the iragai pole ["like a feather"] line... We are both enjoying the music - our eyes cross at one point while we are listening and nodding and we smile at each other over the top of the console... The metronome ticks too, perhaps it's the tempo if his singing that he is adjusting? Yes, I think he is stretching and compressing the sound, piece by piece. And after a few more loops, Y has added an echoing "ohhh" after these lines - does Y hear holes? Or a whole? ... "You feel something is there. Let's try this effect," he replies, affirming virtual presence rather than absence to be filled. The song, in other words, is not a whole to be constituted by filling in holes, but instead ... A couple of listens through and Y gets up: "have some tea or coffee?". . . “Come back tomorrow," $Y$ says: "see how the song turns out."

Looking back at these fragments from my notes - condensed now by my use of ellipses - there are many different rhythms at work in the unfolding of 
this present. There is the building tempo of a process, as singer, composer, and sound engineer work together with microphone, keyboards, speakers, metronome, desktop computer, and software to produce and layer together the elements of a song. There are these fragments of music, bringing humming voice, tapping feet, and shaking heads into consonance with their movement. There is the arc of Yuvan's satisfaction with the song as it comes into being, and as its sounds are juxtaposed in his imagination with the arc of public expectation concerning him. There is the curve of my own surprise and relief at being here to witness this, as though the long-felt vibratory tension of simply seeking access to the happening of such music was suddenly and unexpectedly being slackened, relaxed. These pleasures cross, commingle; smiles are shared across the space of the small room.

But at the same time, what is also registered here is the emergence of a qualitative difference between the openness of his present, and that of my own. For there are at least two different wholes being constituted here: that of his song, but also that of my sense of this process. I was wondering how Yuvan knew what to add to the song, when he would know to add no more. I had asked him if he heard holes in the song, but his response was different, and intriguingly so: he did not feel the absence of something missing but, instead, the presence of something not yet there. He tried out one effect, then another, seeking to find it. But then oddly, in precisely the same way, as I was recording what he was saying, I too was reaching beyond where I had been in my thinking of his doing. "The song, in other words, is not a whole to be constituted by filling in holes, but instead ..."

These ellipses differ from all the others that populate these fragments, for they belong to these notes. I had typed these three dots at Yuvan's studio, almost as an unwitting "effect," in his language, as if to gesture toward the presence of a thought that yet lacked form. Even in their consonance, our rhythms had come to diverge: in the open-ended flux of his present, I had stumbled on an emergent tendency of my own. This was hardly anything, no more than a germinal gap. But perhaps that is just the point. Like weeds of unknown hand and eventual kind, our concepts spring virtually from circumstance.

\section{VIRTUAL, OR FRAGRANT}

In his challenging Anthropology of Time, Alfred Gell argues that there is nothing all that mysterious about time: "The whole world is just one big clock, but it is one which different people can read very differently." ${ }^{42}$ This clock, so to speak, only records "changes in things" before or after the occurrence of other such events. ${ }^{43}$ We ought to look beyond "mental maps" of transformative passage and possibility. 
The world is what it is, and no more: "The real world is not in an alternativeness relationship with itself." 44

Friday, November 12, 2010, 5:43 AM. There is a sensation, something rushing swiftly through my left nostril. I am suddenly awake, blowing my nose. There is a thought, a handful of words. "Variance of something with itself." I feel compelled to write it down.

Not surprisingly, Gell finds Bergson's work deeply flawed. "Bergson's intention was to breathe 'life' into the life sciences," he writes, "an objective he pursued with outstanding literary skill, but no logical acumen, which is why his ideas are, from the point of view of the philosophy of the sciences, as dead as the dodo." $\$ 5$ But just a few pages prior to this declaration, the anthropologist acknowledges the neglect of history, tradition, and memory in his own book, attributing this to his own untimeliness, a "present-focused hunter-gathererish mind-set, coupled toward a certain indifference towards the past and the future." ${ }^{46}$ Gell seems to be implying — perhaps lightly, but still — that there are ways that the past may indeed survive into the present. Are we to repudiate, or to celebrate, this difference of the present with respect to itself?

Monday, March 7, 2011. I'm at my desk, watching myself read a few pages of Matter and Memory. I'd set up my laptop to record myself reading on a Wednesday afternoon in mid-January, just to see what would happen. In 19 minutes of looking down and a few bouts of rustling around, I convey more than anything else the sense of being asleep at the text. I'm bored by the video, more attuned to the pesto in my mouth. Then I see myself writing, circling, underlining. I want to open up the book again - to where Bergson writes of "the inner energy which allows the being to free itself from the rhythm of the flow of things, and to retain in an ever higher degree the past in order to influence ever more deeply the future." Oddly, though, the video reveals only torpor here. My face erupts into a yawn onscreen just eleven seconds after circling these words, "inner energy." 47

What is there to learn from hunter-gatherers, dodoes, and other such untimely beings? Bergson might encourage us to acknowledge that they are still with us - as is everything that has ever been - even if we have trouble discerning their presence. Matter and Memory describes the present forking and moving in two ways at once: as a course of inherited actions and perceptions that draw the past forward as a seamless "flow of things," and as a series of layers of memory that "little by little [come] into view like a condensing cloud." These layers become visible, he writes, only when we undertake "something like the focusing of a camera." 48 This second 
dimension of the past is "essentially virtual," unknowable "unless we follow and adopt the movement by which it expands into a present image, thus emerging from obscurity into the light of day." ${ }^{49}$ This is how memory comes into presence with a promise of freedom. ${ }^{50}$

January 17, 2011. Legs agitated by a bit of strong coffee, I'm reading Lévi-Strauss on "primitives" thousands of miles away. My thoughts stray to my Cumbum family: the image of Sudha carrying coconuts for a wage, Kannan anna and Iswari akka sleeping outside in Tiruppur on a pair of beds with a mosquito coil so that their newly married son can have the single room inside. They are biding their time for just a year till they can return home, while Sudha is enthusiastic only about her daughter Madhu. "School leader," she says with a hopeful laugh; the girl might get government work one day.

Suppose our interlocutors themselves encounter the world as a tissue of echoes, repetitions, and foregone conclusions. What is it to seek, with them, a way of inhabiting such a present as a time of hope and creation? In her Life and Words, Veena Das ponders this question among women who live with the historical violence of Partition. "The presence of rumor in the life of Manjit," Das writes, "lived as that unspoken past that remained virtual - surrounding her relationships yet never given direct expression in speech. ${ }^{51}$ The virtual hovers on the horizons of such life as an "atmosphere" of "poisonous knowledge," its words "like broken shadows of the motion of everyday words." ${ }^{2} 2$ And yet, Das finds another kind of life surfacing in the atmosphere of such remains, through a contagion of the anthropological person: "I cannot think about finding my voice, without imagining what it is to find my voice in the company of others. ${ }^{~} 33$

Wednesday, November 10, 2010. Restless, idling, perplexed, I tap a few keys, click on a button, and I am listening to "Iragai Pole," the song that Yuvan was composing. Oddly, unexpectedly, the opening lines hit me with the sense that they express this very time, this writing, now. "Like a feather, I wander, as I listen to you talk. Like a child, I totter, as I feel your glance." The song was for love; how could it speak so well to what we do in anthropology? We know nothing about how a word appears, lyricist Yugabharathi told me this summer when we met to talk about these lyrics. That is a wonder, he said: like someone who smiles suddenly at us on the street, leading us to wonder why, and then we also smile at others.

As a lingering among the broken shadows of the past, the time of writing is itself a horizon of perceptible "malaise" and "disappointment," Das acknowledges. ${ }^{54}$ A sense of disquiet... I feel this myself, as I try to say what has been happening 
now in this stage of the article. Even the tenses begin to trip me up, as we cut / have cut / been cutting / so much yet to cut / between this unraveling of an argument concerning the virtual in anthropology, and a few glimpses of the virtual horizons of this article itself in the time of its incipience. Forgive me then for only repeating what we have already seen, that the life of what we write cannot but circle constantly back to the endless circumstances of its enlivening. ${ }^{55}$ "In this gesture of waiting," writes Das, "I allow the knowledge of the other to mark me." ${ }^{56}$ We take in the atmosphere of unknown worlds, hoping still to breathe.

Monday, January 10, 2011. Listening to the Paiyya soundtrack, also by Yuvan, with my son Karun. I tap the table loudly with my knuckles as he looks quizzically and turns to his tofu and sweet potatoes. I feel swelling in me a sense of love... I remember the feeling of being on the grass, listening to these same songs in Chennai after a run on the beach. I can feel the soft, well-watered depth into which I sink. A line from a song gives me the reason for this: "Even if the traveler has gone, the footprint will remain along that way. In my life, this instant will remain as a fragrant memory." Remember, there is a theory of memory here as well. Do you like this song, I ask K. "Yeah," he says softly, probably not knowing what else to say.

In India, the image of the past as an atmosphere for life may recall the deep association of memory with fragrance in diverse religious, philosophical, and literary traditions. The fragrance of vāsanā, Shulman writes, "is the karmic trace itself, the subtle stuff of remembering, an intangible, evocative, ambiguous, yet highly specific presence latent in the mind." ${ }^{57}$ Like Bergson's virtual, this is something opening into "an ultimate but hidden reality" that is otherwise imperceptible. ${ }^{58}$ But if Bergson sought a means of overcoming the divisiveness of the intellect, the experience of separation most often engaged here is that of love. South Indian devotional poems are tormented by the tangible yet evanescent scent of the beloved deity: "Like the donkey / laden with a burden of fragrant saffron / harried through a wasteland / half-dead, I stumble / father - trapped / in a whirling vortex." ${ }^{59}$

One spring morning in 2011. A qualifying exam: a graduate student is preparing to leave. We are trying to establish whether she is "ready" for fieldwork, calling up essential arguments, texts, and methods, as well as potential challenges and openings to prepare for. We are satisfied with her answers; she has no questions for us right now. "I just want to go to the field and see what happens. I want to go, and ... "she says, pausing. "I get carried along with the ... "she adds, breaking off again, while her hand continues the movement of her thought, curving out and away again and again, tracing a swerve in the air whose degree and destination cannot yet be plotted. 
Devotion to the fleeting promise of experience ... as in Tamil cinema, which calls for such devotion with the fragrance of the beloved but also with the fragrance of the earth ... as in the film Man Vasanai, in which "only this scent of the soil guards the purity of a culture ... defying the storms, rains, and heat of time” ... as in the spilling of anthropology into such cinema . . . as in the spilling of such cinema into the world . . . as in the flux of the earth I recall with the screen, from a banyan tree, to a Chennai flat, and Cumbum fields, and a pair of slippers, and a fresh young smile, and another tableau ... a as in Proust, who wrote that "the scent of a weakened drop still impregnates my life" ... as in the abandoned hotel room whose broken vials of perfume occasioned these words . . ${ }^{60}$ as in the fragrance of anthropology, drifting like such love as the lingering potential of distant and shattered worlds...

\section{NEWNESS IN ANTHROPOLOGY}

Reflecting darkly on a voyage across the Atlantic in Tristes Tropiques (1972), Claude Lévi-Strauss ponders the contamination of the globe by the detritus of Western civilization. "Mankind has opted for monoculture," he writes, lamenting the erosion of the "perfumes of the tropics and the pristine freshness of human beings." ${ }^{61}$ The anthropologist is tormented both by his imagination of the difference of the past, and by his inability to see the newness of the present. He is paralyzed, he tells us. ${ }^{62}$ But something happens. Time passes, eroding the clarity of these impressions. In their rubble, structures of thought begin to surface like geological formations: "Events without any apparent connection, and originating from incongruous periods and places, slide over the other and suddenly crystallize, into a sort of edifice which seems to have been conceived by an architect wiser than my personal history." ${ }^{63}$ Among the debris of past events, unanticipated possibilities for thought come abruptly into being. ${ }^{64}$

Monday, October 17, 2011. Presented as a talk, this article leads someone to ask whether its interruptions owe too much to literary modernism. I suddenly remember an Indian filmmaker defending his song-and-dance sequences against the charge of unnecessary digression. "This is our way of telling the story," he'd said, invoking the Mahabharata.

Modernity has been taken to mark both the apotheosis and the death-knell of newness. Some would ask us to picture a world of ceaselessly shifting moments, instants, forces, and horizons, and a mode of being most at home among their promises of novel if ephemeral happening. Others ask us to grieve instead over the decay of difference and multiplicity in the contemporary world, and the dwindling 
of our ability even to perceive what difference remains. Still others invite us to reconcile these alternatives, calling attention to ways of navigating the present if not with hope, then at least with less despair. What kind of anthropology is best suited for these times? With what tools should we engage such ruptures, events, and happenings?

We have no choice but to confront these sketches of the fate of newness in our time. Anthropology is a way of thinking in and with the world, the freshness of its insight deeply bound up with the mutable texture of experience and encounter. ${ }^{65}$ This article has sought to acknowledge this relationship between happenings in the world and the happening of our thought. As we traverse the line between empirical life and conceptual possibility, how does newness surface as a quality of what we think and do? Must we shift our attention now to the most visible and powerful laboratories of novelty? Or is there still something creative, inventive, and generative in the condition of being stuck out of joint with the present?

I mean to suggest that everything depends on the sensible quality of such time. This article is nurtured by anthropological traditions of empirical and literary encounter, conveying forms of personal and textual experience against generative horizons of emergence and expression. ${ }^{66}$ Seeking to relay some other world of experience - in the field, to be sure, but also in similarly open circumstances such as reading, writing, and teaching — we are led beyond the foreseeable limits of our own. From this perspective, newness is less a property of certain phenomena, or a promise borne by certain minds or moments, and instead the open weave of potential experience that envelops any endeavor to think with other worlds.

Late July, 2011. The editors of Cultural Anthropology write with disappointing news. Readers find the article promising much more than it actually does; self-absorbed and over-wrought in style, it is "not yet there." I try to plead my case. Here as everywhere, there is more to the field of experience than what is actually present, a generative excess that may be evoked in its fullness without being fully articulated. This mode of expression, I argue, is an attempt at theoretical fidelity and formal precision, rather than an unintended capitulation to vagueness. It is no accident that Nietzsche, Bergson, LéviStrauss, Deleuze, and many others have turned to certain literary devices in pursuit of such arguments, such as the unabashedly Proustian reveries of Tristes Tropiques. Such language bears means to register, convey, evoke, and embody the transformative potential of time, through the palpable impression of the text, and the sensory and affective quality of its experience. To explore how "I is another" is to seek ways of reaching beyond a habitual absorption in oneself, by beginning with the differential texture of one's own implication in time. All of this I propose, and then I wait. 
Like many of those whose lives we share, we remain out of joint, out of time. But for us at least, this is something to acknowledge and embrace, rather than to overcome. As a science of experience - one that takes seriously, as a matter of method, these vicissitudes of movement between self and world, concept and sensation, action and recollection - anthropology involves us in transformative passages of feeling and becoming. ${ }^{67}$ In the manifold encounters that form the rhythm of our work, we may find ourselves caught up, time and again, in times and worlds not entirely our own. Adrift in time as in the world, we attend with love and longing to the inability of things to remain as they are. We become contemporary not by addressing the present as such, but by caring as we can for all that resurfaces alongside it.

\begin{abstract}
This article concerns experience of time in anthropology. It triangulates between theoretical discussions of time, embodiments of temporal experience in a handful of classic and contemporary anthropological works, and the temporal texture of ethnographic fieldwork, reading, and writing. Thinking with philosophers such as Nietzsche, Bergson, and Deleuze, as well as with my disciplinary and field interlocutors and the circumstances of our encounter, I argue that time may be taken as inventive for anthropology insofar as it is untimely, contemporary, present, and virtual in its quality. These four dimensions of time are described as generative insofar as they suffuse anthropological experience with the feeling of being out of joint with the here and now. I argue that the pursuit of newness in contemporary anthropology depends less on the objects of our investigation and more on the temporal and affective relations we nurture with them. Through the use of experimental form, and an alternation between argumentative and expressive language, I seek both to outline and to evoke the importance of time in our encounters with the experiential texture of other worlds. [XXXX, XXXX]
\end{abstract}

\title{
NOTES
}

Acknowledgments. This article is deeply indebted to all those who have taught me to do anthropology and the many institutions that have supported this work. Many others have helped me wrestle with the various forms this article has assumed, most especially Dominic Boyer, Andrew Brandel, Veena Das, Lisa Davis, Lina Dib, Assi Doron, James Faubion, Angela Garcia, Jane Guyer, Niloofar Haeri, Clara Han, Michael Jackson, Naveeda Khan, Harry Marks, Achille Mbembe, Stuart McLean, Urmila Nair, Juan Obarrio, Todd Ochoa, David Platzer, Joel Robbins, Rupert Schasch, Kathleen Stewart, and Chitra Venkatramani. I learned tremendously from discussions of this article at The Australian National University, Johns Hopkins University, and the University of California, San Diego. I am grateful to my anonymous reviewers and hope I have met some of the difficult challenges they posed. Finally, I am inspired by the vision and generosity of Anne Allison and Charles Piot.

1. See Fischer (2003).

2. See Augé (1999:50-1).

3. See Allison and Piot (2011:3), Rabinow and colleagues (2008), and Hamilton and Placas (2011). 
4. "Anthropologists are increasingly studying timely phenomena with tools developed to study people out of time," observes Tobias Rees, for example, describing the turn to concerns such as technoscience, finance, media, and law (Rabinow et al. 2008:13).

5. See, especially, Gell (1992), Munn (1992), Desjarlais (2003), and Guyer (2007).

6. See Fabian $(1983: 21,31)$.

7. See Bergson $(2005: 12)$.

8. See Deleuze (1985: vii-xiii, 1989:78-83) on the "out of joint" temporality of subjectivity.

9. See Taussig (2003:154).

10. On field notes and ethnographic texts, see Sanjek (1990).

11. My concern here is less with "how it happened, in [fieldwork's] real time" (Malkki and Cerwonka 2007:186) than with the happening of anthropological thought as an ongoing and potentially limitless movement of temporal return. This point is conveyed beautifully by Obarrio (2011).

12. See, for example, Marcus on the value of displacing "the mythos of fieldwork and the informal professional culture that supports it" (2009:27).

13. Lévi-Strauss (1976:36), quoting from Rimbaud.

14. "This much is clear: I'm around for the hatching of my thought: I watch it, I listen to it: I release a stroke from the bow: the symphony makes its rumblings in the depths, or leaps fully-formed onto the stage" (Rimbaud 2002:366).

15. See Nietzsche (1997:68).

16. See Nietzsche (1997:60).

17. See Nietzsche $(1997: 146)$ on Schopenhauer.

18. See Nietzsche (1997:60).

19. See Nietzsche (1997:63-64).

20. Okely (2007:361) notes that almost all of the 22 anthropologists she interviewed about their fieldwork reported changing their intended focus "some time after arrival."

21. See Rabinow (2008:49).

22. See Rabinow and colleagues (2008:59).

23. See Rabinow and colleagues (2008:69). See Rabinow (2008:33-50) on a lonely "adjacency" with scientists.

24. See Rabinow (2008:1).

25. See Rabinow (2008:2).

26. See Rabinow (2008:5).

27. On temporal divergences between anthropologists and their interlocutors, see Augé (1999:47).

28. See Koselleck (2004:266) on the "the contemporaneity of the non-contemporaneous."

29. On "our own movement in time with those with whom we work," see Han (2011:26).

30. On the differential subjectivity at stake in such coincidence, see Bergson (2005:219).

31. See Stewart (2007:1).

32. See Stewart (2007:9).

33. See Stewart (2007:41).

34. Stewart (2007:128).

35. See Bergson (2007b:5).

36. See Bergson (2007b:7-8).

37. See Bergson (2007a:126).

38. See Deleuze (1991:32).

39. See Stewart (2007:5).

40. See Stewart $(2007: 126)$.

41. See Stewart (2007:35).

42. See Gell (1992:96).

43. See Gell (1992:161).

44. See Gell (1992:217).

45. See Gell (1992:317).

46. See Gell (1992:314).

47. See Bergson (2004:296) 
48. See Bergson (2004:171).

49. See Bergson (2004:173).

50. See Bergson (2004:296).

51. See Das (2007:100).

52. See Das $(2007: 76,89)$.

53. See DiFruscia (2010:139).

54. See Das (2007:2-3).

55. Looking back in retrospect at this section, it has come to appear to me as a textual embodiment of a crucial image in Bergson's Matter and Memory (2004:128), which depicts the apperception of an object as a paired series of concentric circles, linked along one span in the manner of a seashell: one series of concentric circuits representing successive images of its actual perception, and the other representing successive depths of its virtual recollection.

56. See Das (2007:17).

57. See Shulman $(1987: 126)$.

58. See Shulman (1987:125).

59. From the early medieval Tamil Tevaram, as cited by Shulman (1987:133).

60. See Proust (2006:211).

61. See Lévi-Strauss (1972:37-38).

62. See Lévi-Strauss (1972:43).

63. See Lévi-Strauss (1972:44).

64. On generative time in anthropology, note this passage: "the principle underlying a classification can never be postulated in advance. It can only be discovered a posteriori by ethnographic investigation, that is, by experience" (Lévi-Strauss 1966:58).

65. See Jackson (2009).

66. On the Romantic horizons of such traditions, see Crapanzano (2004).

67. I am concerned less with a delimited "anthropology of becoming" (Biehl and Locke 2010, emphasis added) than the wider and significant promise of anthropology as becoming.

\section{REFERENCES CITED}

Allison, Anne, and Charles Piot

2011 New Editors' Greeting. Cultural Anthropology 26(1):1-5.

Augé, Marc

1999 For an Anthropology of Contemporaneous Worlds. Stanford: Stanford University Press.

Bergson, Henri

2004 Matter and Memory. New York: Dover.

2005 Creative Evolution. New York: Cosimo.

2007a Creative Mind. New York: Dover.

2007b An Introduction to Metaphysics. New York: Palgrave Macmillan.

Biehl, João, and Peter Locke

2010 Deleuze and the Anthropology of Becoming. Current Anthropology 51(3):317351.

Crapanzano, Vincent

2004 Imaginative Horizons: An Essay in Literary-Philosophical Anthropology. Chicago: University of Chicago Press.

Das, Veena

2007 Life and Words: Violence and the Descent into the Ordinary. Berkeley: Deleuze, Gilles University of California Press.

1985 Kant's Critical Philosophy. Minneapolis: University of Minnesota Press.

1989 Cinema 2: The Time-Image. Minneapolis: University of Minnesota Press.

1991 Bergsonism. New York: Zone. 
Desjarlais, Robert

2003 Sensory Biographies: Lives and Deaths among Nepal's Yolmo Buddhists.

DiFruscia, Kim Berkeley: University of California Press.

2010 Listening to Voices: An Interview with Veena Das. Altérités 7(1):13645 .

Fabian, Johannes

1983 Time and the Other: How Anthropology Makes its Object. New York: Columbia University Press.

Fischer, Michael M. J.

2003 Emergent Forms of Life and the Anthropological Voice. Durham, NC: Duke University Press.

Gell, Alfred

1992 The Anthropology of Time: Cultural Constructions of Temporal Maps and Images. Oxford: Berg.

Guyer, Jane

2007 Prophecy and the Near Future: Thoughts on Macroeconomic, Evangelical, and Punctuated Time. American Ethnologist 34(3):409-421.

Hamilton, Jennifer, and Aimee Placas

2011 Anthropology Becoming...? The 2010 Sociocultural Anthropology Year in Review. American Anthropologist 113(2):246-261.

Han, Clara

2011 Symptoms of Another Life: Time, Possibility, and Domestic Relations in Chile's Credit Economy. Cultural Anthropology 26(1):7-32.

Jackson, Michael

2009 Where Thought Belongs: An Anthropological Critique of the Project of Philosophy. Anthropological Theory 9(3):235-251.

Koselleck, Reinhart

2004 Futures Past: On the Semantics of Historical Time. New York: Columbia University Press.

Lévi-Strauss, Claude

1966 The Savage Mind. Chicago: University of Chicago Press.

1972 Tristes Tropiques. New York: Penguin.

1976 Jean-Jacques Rousseau, Founder of the Sciences of Man. In Structural Anthropology, vol. 2. Pp. 33-43. London: Allen Lane.

Malkki, Lisa, and Allaine Cerwonka

2007 Improvising Theory: Process and Temporality in Ethnographic Fieldwork.

Marcus, George Chicago: University of Chicago Press.

2009 Introduction: Notes toward an Ethnographic Memoir of Supervising Graduate Research through Anthropology's Decades of Transformation. In Fieldwork Is Not What It Used to Be: Learning Anthropology's Method in a Time of Transition. James D. Faubion and George E. Marcus, eds. Pp. 1-31. Ithaca, NY: Cornell University Press.

Munn, Nancy D.

1992 The Cultural Anthropology of Time: A Critical Essay. Annual Review of Anthropology 21:93-123.

Nietzsche, Friedrich

1997 Untimely Meditations. Cambridge: Cambridge University Press.

Obarrio, Juan

2011 ER ( . . . ) Ellipses. Social Text 29(2):121-127.

Okely, Judith

2007 Response to George Marcus. Social Anthropology 15(3):351-361. 
Proust, Marcel

2006 Another Memory. In The Smell Culture Reader. Jim Drobnick, ed. Pp. 210-211. New York: Berg.

Rabinow, Paul

2008 Marking Time: On the Anthropology of the Contemporary. Princeton: Princeton University Press.

Rabinow, Paul, George Marcus, James Faubion, and Tobias Rees

2008 Designs for an Anthropology of the Contemporary. Durham, NC: Duke University Press.

Rimbaud, Arthur

2002 Rimbaud Complete. New York: Modern Library.

Sanjek, Rojer

1990 On Ethnographic Validity. In Fieldnotes: The Makings of Anthropology.

Cornell: Cornell University Press.

Shulman, David

1987 The Scent of Memory in Hindu South India. Res 13:122-133.

Stewart, Kathleen

2007 Ordinary Affects. Durham, NC: Duke University Press.

Taussig, Michael

2003 Law in a Lawless Land: Diary of a Limpieza. Chicago: University of Chicago Press. 
cuan_1161 can2008.cls September 10, $2012 \quad$ 17:31

\section{Query}

Q1 Author: Please supply between 4 and 7 key words or phrases. 